\title{
Extrapulmonary Small Cell Carcinoma of the Stomach: A Lethal Entity
}

\author{
Duane Moise Jaspreet Singh Keith Dahl Sadat Rashid \\ Apsara Prasad Ghulam Siddiqui Krishnaiyer Subramani \\ Paul Mustacchia Kaleem Rizvon
}

Department of Gastroenterology, Nassau University Medical Center, East Meadow, N.Y., USA

\section{Key Words}

Gastric small cell carcinoma $\cdot$ Extrapulmonary small cell carcinoma $\cdot$ Pure $\cdot$ Composite

\begin{abstract}
Extrapulmonary small cell carcinoma of the stomach is a rare and aggressive malignancy with a poor prognosis that was first described in 1976 by Matsusaka et al. In 1989 it was recognized by the World Health Organization as an independent entity affecting the stomach. Pure and composite are the two types of gastric small cell carcinoma reported in the literature. We report a case of a 68-year-old African American male with metastatic pure-type extrapulmonary small cell cancer of the stomach. The primary lesion measured approximately $7 \mathrm{~cm}$ in diameter on endoscopy. The diagnosis was made on the basis of characteristic histological features of small, round, oval lymphocyte-like cells with hyperchromatic nuclei, and scant cytoplasm consistent with small cell carcinoma. Gastric small cell carcinoma is typically diagnosed at an advanced stage as demonstrated in our case. We conducted a literature review discussing the two types of extrapulmonary small cell carcinoma of the stomach and their prevalence.
\end{abstract}

\section{Introduction}

Gastric small cell carcinoma (GSCC) is a rare and often fatal malignancy that was first described in 1976 by Matsusaka et al. [1]. As of 2008, 107 GSCC cases have been reported in the literature [2]. Most reported cases have occurred in Japan, and directly correlate with aggressive screening measures for gastric malignancy. GSCC accounts for $0.1 \%$ of all histologic specimens of gastric tumors [1]. There is usually evidence of metastatic disease at diagnosis leading to a poor prognosis. Matsusaka et al. reported two types, pure-type and composite-type. Pure-type GSCC is based on histologic specimens in which no other tumor types are identified, i.e. adenocarcinoma or squamous cell 
carcinoma. Composite-type GSCC consists of a mixture of adenocarcinoma and/or squamous cell carcinoma along with small cell carcinoma.

\section{Case Report}

A 68-year-old African American male presented to the gastroenterology practice with lethargy, jaundice, unintentional weight loss and abdominal distension. He had no significant past medical or family history. Social history was significant for alcohol abuse with consumption of a six pack of beer every other day; there was no history of tobacco or recreational drug use.

Physical examination revealed a cachectic man with bitemporal wasting, dry mucous membranes, scleral icterus, abdominal distension consistent with ascites, scrotal and bilateral pitting pedal edema. Laboratory tests revealed a hemoglobin of $9.3 \mathrm{~g} / \mathrm{dl}$, hematocrit $27 \%$, aspartate aminotransferase (AST) $314 \mathrm{U} / \mathrm{l}$, alanine aminotransferase (ALT) $211 \mathrm{U} / \mathrm{l}$, alkaline phosphatase (ALP) 1,158 U/l and a total bilirubin of $14.8 \mathrm{mg} / \mathrm{dl}$ with a direct fraction of $12.1 \mathrm{mg} / \mathrm{dl}$. The patient was admitted to the medical floor for intravenous hydration and diagnostic assessment.

Abdomen ultrasonography was performed and revealed multiple solid-appearing liver lesions suspicious for a metastatic process and moderate ascites. Computed tomography (CT) scan of the abdomen demonstrated a complex low density lesion measuring $7 \times 6 \times 5 \mathrm{~cm}$ in the right hepatic lobe of the liver, cystic masses surrounding the pancreatic head and neck, heterogeneous thickening surrounding the gastric fundus, omental caking, and a nodular shrunken liver suggestive of cirrhosis (fig. 1). An esophagogastroduodenoscopy (EGD) was performed which revealed a large circumferential infiltrating mass of approximately $7 \mathrm{~cm}$ in diameter involving the cardia and fundus (fig. 2). Histologic examination of the specimens obtained from the gastric mass revealed small, round, oval lymphocytelike cells with hyperchromatic nuclei, scant cytoplasm, and frequent mitoses compatible with small cell carcinoma (fig. 3 ).

Immunohistochemical staining was negative for neuron-specific enolase, synaptophysin, and chromogranin A. The patient's CEA and CA 19-9 level were $2.7 \mathrm{ng} / \mathrm{ml}$ and $585 \mathrm{U} / \mathrm{ml}$, respectively. A subsequent chest CT did not reveal any significant lung lesions suggestive of a primary small cell lung cancer.

The patient was evaluated by oncology and due to the patient's advanced tumor stage and comorbidities, was deemed a poor candidate for cytotoxic chemotherapy. The patient was placed under palliative care. Hospital course was complicated by episodes of hypoglycemia, increasing lethargy, change in mental status and large volume hematemesis. The patient subsequently died on day 16 of hospitalization.

\section{Discussion}

Small cell carcinoma is a malignancy frequently observed in the lungs [3], but extrapulmonary small cell carcinoma (EPSCC) is rare. EPSCC has been reported from the gastrointestinal tract, head and neck, urinary tract and genital organs [2, 4]. Brenner et al. reported that most small cell carcinoma of the gastrointestinal tract involved the esophagus in $53 \%$ of the 544 reported cases. The colon (13\%) and the stomach (11\%) were the second and the third most common sites respectively [5].

The incidence of GSCC appears to be underestimated [5]. Based on the literature there remains a discrepancy in the actual number of reported cases. Namikawa et al. reported 107 published cases of GSCC [2]. Tanemura et al. reported 67 cases in Japan alone as of 2002 [6]. Fukuda et al. reported a patient found to have foci of small cell carcinoma in the gastrectomy specimen for well-differentiated tubular adenoma [7]. As stated previously, GSCC consists of a pure-type and mixed or composite-type. The composite types demonstrate glandular and/or squamous differentiation [8]. We have reviewed the classification of a number of GSCC cases reported in the literature and their histological 
characteristics (table 1). As described in table 1, the number of cases of pure-type and composite-type gastric small cell cancer is approximately equivalent.

Although many theories have been postulated, the origin of small cell carcinoma remains unclear. Small cell carcinoma is thought to originate from preexisting neuroectodermal cells, pluripotent epithelial stem cells, or adenocarcinoma precursor cells. Matsui et al. suggested that these tumors originate from totipotent primitive cells which can lead to dual or multiple differentiation, including a mixture of small neoplastic cells, squamous cells and adenocarcinomatous cells [8]. The diagnosis is made by histologic review of endoscopic or surgical biopsy specimen.

Cases of histologically proven gastric adenocarcinoma may contain cellular features consistent with small call carcinoma. As a result inadequate biopsy sampling may account for the underestimation in its incidence. Histology as well as immunohistochemistry are considered to be the hallmark of pathological diagnosis. Neuron-specific enolase, chromogranin and Grimelius staining are used for immunohistochemical diagnosis [2]. Tanemura et al. reported that chromogranin, neuron-specific enolase and Grimelius staining were positive in $72.2,62.2$, and $54.2 \%$ respectively in the reported cases of gastric small cell carcinoma in whom these staining methods were used [6]. In addition, it is important to note that in $10-20 \%$ of cases of GSCC, immunohistochemical staining for the aforementioned tumor markers may yield negative results as demonstrated in our patient. Tanemura et al. have suggested that the final diagnosis should be based on routine morphologic features seen on light microscopy as immunohistochemistry can be negative in some cases [6]. CEA staining can be used to rule out adenocarcinoma [9]. CD56 markers can also be used to differentiate between small cell carcinoma and large cell carcinoma [13].

The natural history of GSCC is comparable to that of pulmonary small cell carcinoma. GSCC predominantly occurs in males in their mid sixties $[2,6,8,9]$. Most of the cases were reported from Japan, several cases from Western countries have also been published. Presenting symptoms are often identical to gastric adenocarcinoma. Patients present with epigastric pain, nausea, anorexia, early satiety, and weight loss [8]. Based on the largest reviews of histologically proven GSCC by Namikawa et al. (107 patients) [2] and Tanemura et al. (67 patients) [6], these tumors usually occur in the upper-third of the stomach. The average tumor size varies from 0.8 to $17 \mathrm{~cm}$ as reported by Namikawa et al. [2]. Matsui et al. reported an average size ranging from 1 to $11 \mathrm{~cm}$ [8]. The mass can be polypoid or ulcerating depending upon its size $[8,9]$. Since GSCC tumor incidence is low, no proper classification for tumor staging or grading has been assigned. There is not a well established staging classification for GSCC tumors. GSCC often behaves like pulmonary small cell carcinoma, micrometastasis is considered to be present at early stages.

There is no consensus regarding treatment regimens. Since extrapulmonary small cell carcinoma is very aggressive, some authors recommend that it be treated similarly to pulmonary small cell carcinoma $[1-3,7,9,11,14]$. Preoperative chemotherapy has been used and is recommended by someone $[9,15]$. Intensive chemotherapy in postsurgical resection patients has also been recommended $[1,14]$. Chemotherapeutic agents including cyclophosphamide, doxorubicin and vincristine [3], etoposide/visplatin [4], mitomycin, tegafur [8], cisplatin and adriamycin $[8,9]$ have been tried with varying results. Nakamura et al. reported a good response to neoadjuvant chemotherapy with carboplatin, epirubicin, etoposide and 5-flurouracil leading to marked reduction in the primary tumor and lymph node metastases [15]. Recently, 5-fluorouracil, etoposide and lederfolin combination chemotherapy was used in a patient described by Cioppa et al. [1]. 
The same patient received intraarterial hepatic chemotherapy with cisplatin, adriamycin and mitomycin-C for the hepatic metastasis [1]. A partial response was described.

Chemotherapy and radiotherapy should be considered in cases of inoperable GSCC. Prognosis is often worse than undifferentiated adenocarcinoma of the stomach. The majority of patients with GSCC survive less than one year $[2,8,9]$.

\section{Conclusion}

Our patient with GSCC is one of the few reported cases in the literature outside of Japan. Based on our literature review, we conclude that there is no difference in the prevalence of pure type and composite type GSCC. It is important to note that cases of composite GSCC may be misdiagnosed as pure type GSCC due to sampling error. The location and quantity of specimens obtained from suspicious gastric masses may play a role in accurately establishing the diagnosis of GSCC. Further studies need to be performed providing guidelines for the evaluation and management of these uncommon malignancies.

Table 1. Review of the literature demonstrating the number of cases of GSCC reported and their histological classification into pure and composite types

\begin{tabular}{llrrrl}
\hline Year & Author & $\begin{array}{l}\text { Reported } \\
\text { cases }\end{array}$ & Pure & Composite & $\begin{array}{l}\text { Not } \\
\text { determined }\end{array}$ \\
\hline 2005 & Namikawa et al. [2] & 107 & $41(38.3 \%)$ & $44(41.1 \%)$ & 22 \\
2003 & Kusayanagi et al. [9] & 38 & $14(36.8 \%)$ & $24(63.1 \%)$ & NA \\
2002 & Tanemura et al. [6] & 66 & $32(48.4 \%)$ & $33(50.0 \%)$ & 1 \\
1999 & Takaku et al. [10] & 32 & $14(43.7 \%)$ & $18(56.2 \%)$ & NA \\
1998 & Arai and Matsuda [11] & 54 & $24(44.4 \%)$ & $30(55.5 \%)$ & NA \\
1997 & Sato et al. [12] & 11 & $5(45.4 \%)$ & $6(54.5 \%)$ & NA \\
1991 & Matsui et al. [8] & 17 & $5(29.4 \%)$ & $12(70.4 \%)$ & NA \\
1990 & Hussein et al. [3] & 8 & $4(50.0 \%)$ & $4(50.0 \%)$ & NA \\
1988 & Fukuda et al. [7] & 4 & $2(50.0 \%)$ & $2(50.0 \%)$ & NA \\
\hline
\end{tabular}

NA $=$ Not applicable. 


\begin{tabular}{r|l|l|l} 
Case Reports in & $\begin{array}{l}\text { Case Rep Gastroenterol 2010;4:298-303 } \\
\text { D01: 10.1159/000314821 }\end{array}$ & Published online: August 27, 2010 & $\begin{array}{l}\odot \text { 2010 S. Karger AG, Basel } \\
\text { ISSN 1662-0631 } \\
\text { www.karger.com/crg }\end{array}$ \\
\hline
\end{tabular}

Fig. 1. Moderate ascites, heterogenous thickening surrounding the gastric fundus, omental caking, nodular shrunken liver consistent with cirrhosis.

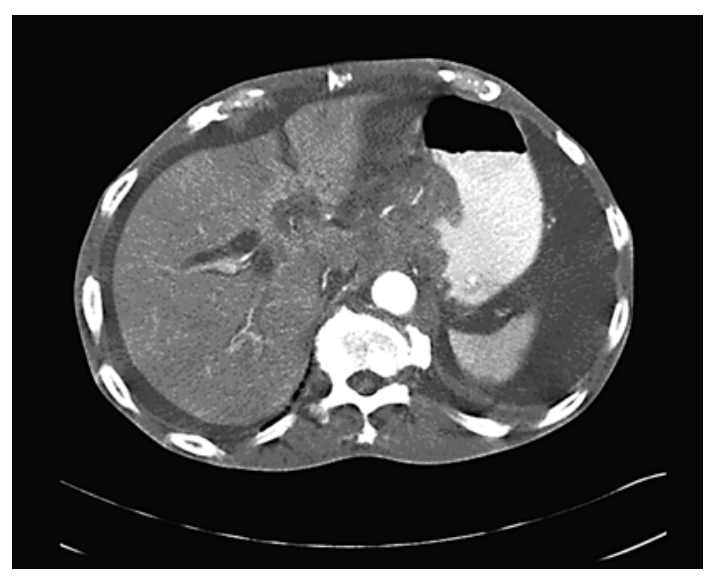

Fig. 2. Endoscopic retroflexed view of the fundal mass.

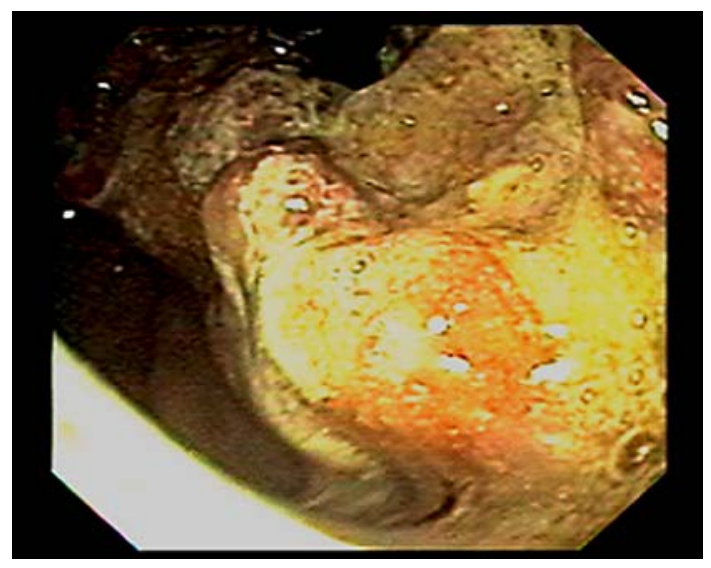

Fig. 3. Small, round lymphocyte-like cells with hyperchromatic nuclei, scant cytoplasm and frequent mitosis on light microscopy.

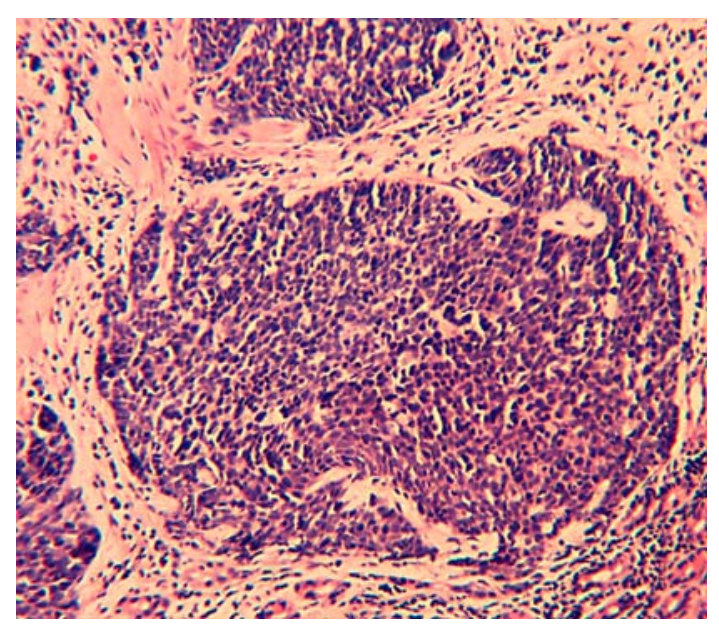




\section{References}

1 Cioppa T, Marrelli D, Neri A, Caruso S, Pedrazzani C, Malagnino V, Pinto E, Roviello F: A case of small-cell gastric carcinoma with an adenocarcinoma component and hepatic metastasis: treatment with systemic and intra-hepatic chemotherapy. Eur J Cancer Care 2007;16:453-457.

-2 Namikawa T, Kobayashi M, Okabayashi T, Ozaki S, Nakamura S, Yamashita K, Ueta H, Miyazaki J, Tamura S, Ohtsuki Y, Araki K: Primary gastric small cell carcinoma: report of a case and review of the literature. Med Mol Morphol 2005;38:256-261.

-3 Hussein AM, Otrakji CL, Hussein BT: Small cell carcinoma of the stomach: case report and review of the literature. Dig Dis Sci 1990;35:513-518.

-4 Kim JH, Lee SH, Paek J, Kim HY, Lee SI, Nam WM, Park JO, Kim K, Jung CW, Im YH, Kang WK, Lee MH, Park K: Extrapulmonary small-cell carcinoma: a single-institution experience. Jpn J Clin Oncol 2004;34:250-254.

-5 Brenner B, Tang LH, Klimstra DS, Kelsen DP: Small cell carcinoma of the gastrointestinal tract: a review. J Clin Oncol 2004;22:2730-2739.

6 Tanemura H, Ohshita H, Kanno A, Kusakabe M, Tomita E, Nishigaki Y, Sugiyama A, Yamada T: A patient with small-cell carcinoma of the stomach with long term survival after percutaneous microwave coagulating therapy (PMCT) for liver metastasis. Int J Clin Oncol 2002;7:128-132.

-7 Fukuda T, Ohnishi Y, Nishimaki T, Ohtani H, Tachikawa S: Early gastric cancer of the small cell type. Am J Gastroenterol 1988;83:1176-1179.

8 Matsui K, Kitagawa M, Miwa A, Kuroda Y, Tsuji M: Small cell carcinoma of the stomach: a clinicopathologic study of 17 cases. Am J Gastroenterol 1991;86:11671175.

-9 Kusayanagi S, Konishi K, Miyasaka N, Sasaki K, Kurahashi T, Kaneko K, Akita Y, Yoshikawa N, Kusano M, Yamochi T, Kushima M, Mitamura K: Primary small cell carcinoma of the stomach. J Gastroenterol Hepatol 2003;18:743-747.

10 Takaku H, Oka K, Naoi Y, Santoh N, Setsu Y, Mori N: Primary advanced gastric small cell carcinoma: a case report and review of the literature. Am J Gastroenterol 1999;94:1402-1404.

11 Arai K, Matsuda M: Gastric small-cell carcinoma in Japan: a case report and review of the literature. Am J Clin Oncol 1998;21:458-461.

-12 Sato T, Sakuma H, Isobe T, Naka F, Ueda H, Matsubara F, Nonomura A: Concurrent small-cell carcinoma and adenocarcinoma of the stomach. Dig Surg 1997;14:61-64.

13 Shpaner A, Yusuf TE: Primary gastric small-cell neuroendocrine carcinoma. Endoscopy 2007;39:E310-E311.

14 Sun YL, Liu YW, Zhong DR, Gao WS: Gastric small cell carcinoma: 6 cases report and review of literature (in Chinese). Zhonghua Wai Ke Za Zhi 2008;46:756-758.

-15 Nakamura Y, Otani S, Otaka M, Shimada T, Takahashi S, Saito M, Takhashi T, Komatsu M, Suzuki T, Okubo S, Hayashi M, Sasano H: Gastric small cell carcinoma with a marked response to neoadjuvant chemotherapy. Int J Clin Oncol 2005;10:348-352. 